\title{
Prehospital quick Sequential Organ Failure Assessment for predicting prognosis in patients with sepsis or suspected sepsis: a population- based ORION registry
}

Tomoya Hirose ( $\sim$ htomoya1979@hp-emerg.med.osaka-u.ac.jp )

Osaka University Graduate School of Medicine

Yusuke Katayama

Osaka University Graduate School of Medicine Hiroshi Ogura

Osaka University Graduate School of Medicine

Yutaka Umemura

Osaka University Graduate School of Medicine

Tetsuhisa Kitamura

Osaka university Graduate School of Medicine

Yasuaki Mizushima

Osaka Police Hospital

Takeshi Shimazu

Osaka University Graduate School of Medicine

Original research

Keywords: Infection, Survival, Emergency medical service

Posted Date: July 24th, 2020

DOI: https://doi.org/10.21203/rs.3.rs-42846/v1

License: (c) (i) This work is licensed under a Creative Commons Attribution 4.0 International License.

Read Full License 


\section{Abstract}

\section{Background}

In 2016, the quick Sequential Organ Failure Assessment (qSOFA) was proposed for use as a simple screening tool for sepsis, with sepsis suspected at a score $\geq 2$ points. In this study, we evaluated the effectiveness of prehospital qSOFA for predicting prognosis in patients with sepsis or suspected sepsis using the population-based Osaka Emergency Information Research Intelligent Operation Network (ORION) registry, which compiles prehospital ambulance data and in-hospital information.

\section{Methods}

The study enrolled 437,974 patients in the ORION registry from January 1 to December 31,2016 . We selected hospitalized patients with sepsis or suspected sepsis using the appropriate ICD 10 codes. We excluded the patients with i) missing data (outcome, Japan Coma Scale, respiratory rate, blood pressure), ii) respiratory rate $\geq 60 / \mathrm{min}$, and iii) blood pressure $\geq 250 \mathrm{mmHg}$. These measures were evaluated by ambulance personnel when they first contacted the patient in the prehospital setting. The primary endpoint was discharge to death.

\section{Results}

In total, 12,646 patients (median age: 78 [IQR: 65-85] years, male: $n=6760$ [53.5\%]) were eligible for our analysis. In a multivariable logistic regression analysis adjusted for confounding factors, the proportion of patients discharge to death was significantly higher for qSOFA positive ( $\geq 2$ points) than negative ( $\leq 1$ point) $(265 / 2250$ [11.78\%] vs. $415 / 10,396$ [3.99\%]; adjusted odds ratio $2.909 ; 95 \%$ confidence interval $2.469-3.428, p<0.0001)$. The specificity and sensitivity were $83.4 \%$ and $40.0 \%$, respectively, and the area under the receiver operating characteristic curve for qSOFA positive was 0.61 .

\section{Conclusions}

qSOFA evaluated by emergency medical services personnel in the prehospital setting might be useful for predicting prognosis in patients with sepsis or suspected sepsis.

\section{Background}

In 2016, the Third International Consensus Definitions Task Force defined sepsis as 'life-threatening organ dysfunction due to a dysregulated host response to infection', and the quick Sequential Organ Failure Assessment (qSOFA) was proposed for use as a simple screening tool for sepsis, with sepsis being suspected at a score $\geq 2$ points [1]. Due to its simplicity, qSOFA has high affinity in situations in which the examination environment is not prepared and in pre-hospital settings [2]. However, several studies in the prehospital setting have shown that there are large differences in its diagnostic and prognostic abilities due to the small and limited study groups examined [3-7]. Therefore, the true 
assessment ability of qSOFA in the prehospital setting has not been fully clarified. To resolve this issue, comprehensive regional analysis is required.

The Osaka Prefecture Government has developed and introduced an information system for emergency patients transported by emergency medical service (EMS) personnel (the Osaka Emergency Information Research Intelligent Operation Network [ORION] system), which compiles prehospital ambulance records and in-hospital information such as diagnosis and prognosis [8].

In the present study, we attempted to evaluate the effectiveness of the prehospital use of qSOFA for predicting prognosis in patients with sepsis or suspected sepsis using the population-based ORION registry.

\section{Methods}

\section{Study design, population, and setting}

This was a retrospective observational study using the ORION database [8]. The study period spanned 1 year from January 2016 to December 2016. Osaka Prefecture is located in the western area of Japan, covers an area of $1905 \mathrm{~km}^{2}$, and has a population of 8.8 million. The proportion of male inhabitants was $48.1 \%$ and that of elderly people (aged $\geq 65$ years) was $26.1 \%$ in 2015 [8]. There are 519 hospitals (106,273 beds) in Osaka Prefecture, of which 288 are emergency hospitals including 16 critical care centers that are designated to accept patients with life-threatening emergency conditions such as severe trauma and sepsis [8].

We included all emergency patients registered in the ORION database. We selected hospitalized patients with sepsis or suspected sepsis using the ICD (International Statistical Classification of Diseases and Related Health Problems) 10 codes shown in Supplementary Table 1. Each ICD 10 code was evaluated after hospital admission by physicians. Next, we excluded the following patients: those with i) missing data (outcome, Japan Coma Scale [JCS], respiratory rate, blood pressure), ii) respiratory rate $\geq 60 / \mathrm{min}$, and iii) blood pressure $\geq 250 \mathrm{mmHg}$. These were evaluated by ambulance personnel when they first contacted the patient in the prehospital setting.

This study was approved by the Ethics Committee of the Osaka University Graduate School of Medicine (No. 15003). Personal identifiers were removed beforehand from the ORION database, and thus the patients' right to informed consent was waived. This study was conducted based on the ORION database under the present researchers' responsibility, and it differs from the statistics published by Osaka Prefecture. This research was not conducted by Osaka Prefecture. This study was written based on the STROBE statement to assess the reporting of cohort and cross-sectional studies [9].

\section{ORION}


In January 2013, the Osaka Prefecture Government first developed and introduced an information system for emergency patients (the Osaka Emergency Information Research Intelligent Operation Network [ORION] system) that uses a smartphone app for hospital selection by on-scene EMS personnel and since then, it has been accumulating all ambulance records. Furthermore, since January 2015, medical institutions have registered information on the diagnosis and outcome of emergency patients transported to medical institutions, and the ORION system has merged these data with the respective ambulance records and smartphone app data. This report describes the ORION system and its profile of hospital information, EMS characteristics, and in-hospital diagnoses and outcomes.

\section{qSOFA score}

The qSOFA was introduced with the Sepsis-3 criteria. The score ranges from $0-3$ with 1 point assigned for each of the following criteria met by the patient: systolic arterial blood pressure $\leq 100 \mathrm{mmHg}$; respiratory rate $>21$ breaths/min; or altered mental status [1]. For the prehospital evaluation of mental status, Japanese EMS providers have adopted the JCS instead of the Glasgow Coma Scale since its introduction in 1974 [10]. The JCS has four main grades (grade 0: alert; grade 1: possible verbal response without any stimulation, not lucid; grade 2: possible eye-opening, verbal and motor response upon stimulation; and grade 3: no eye-opening and coma upon stimulation). Therefore, in this study, an evaluation other than JCS 0 (alert) was defined as 'altered mental status' and was considered equal to a Glasgow Coma Scale score of $\leq 14$.

\section{Endpoint}

The primary endpoint was discharge to death.

\section{Statistical analysis}

Patient characteristics and outcomes were evaluated between two groups using the Wilcoxon rank-sum test for continuous variables and the chi-square test or Fisher's exact test for categorical variables. Oneway analysis of variance (ANOVA) was used to evaluate the differences in mortality according to the qSOFA score. Multivariable analysis of the eligible patients was used to assess factors associated with the outcomes by using logistic regression models, and adjusted odds ratios (AORs) and their $95 \%$ confidence intervals (Cls) were calculated. Potential confounding factors (age [continuous value] and sex [male, female]) based on biological plausibility and previous studies were included in the multivariable analysis. To analyze the effectiveness of qSOFA positive/negative for predicting hospital mortality, we created a receiver operating characteristic (ROC) curve. A $p$ value of $\leq 0.05$ was considered significant. All statistical analyses were performed using JMP Pro 13 (SAS Institute Inc., Cary, NC, USA).

\section{Results}

\section{Patient characteristics}


Figure 1 shows the patient flow in this study. During the study period, 437,974 emergency patients were registered in the ORION. Among them, 174,990 patients were hospitalized. Next, 27,977 patients were selected as patients with sepsis or suspected sepsis using the appropriate ICD-10 codes (Supplementary Table 1). We excluded the following patients: (i) JCS 'Missing data' ( $n=13,447)$; (ii) respiratory rate: 'Missing data' or ' $\geq 60 / \mathrm{min}^{\prime}$ ( $\left.n=14,624\right)$; (iii) blood pressure 'Missing data' or ' $\geq 250 \mathrm{mmHg}$ ' $(n=14,331)$; (iv) outcome at hospital discharge 'Missing data' $(n=48)$. Finally, 12,646 patients were eligible for our analysis. Among them, 680 (5.4\%) died in the hospital.

Patient characteristics are shown in Table 1. Compared to the patients with qSOFA score $\leq 1$, those with a qSOFA score $\geq 2$ were more likely to be older and female and to have a lower level of consciousness, higher respiratory rate, and lower systolic blood pressure.

Table 1

Patient characteristics

\begin{tabular}{|c|c|c|c|}
\hline Characteristic & $\begin{array}{l}\text { qSOFA score } \\
\geq 2\end{array}$ & $\begin{array}{l}\text { qSOFA score } \\
\leq 1\end{array}$ & $p$ Value \\
\hline N & 2250 & 10396 & \\
\hline Age, years, median (IQR) & $81(70-87)$ & $77(63-85)$ & $\stackrel{<}{0.0001}$ \\
\hline Sex, Male, n (\%) & $1139(50.6)$ & $5621(54.1)$ & 0.0031 \\
\hline Japan Coma Scale, n (\%) & & & $\dot{0} 00001$ \\
\hline 0 (Alert) & $276(12.3)$ & $8425(81.0)$ & \\
\hline I (Delirium, confusion, senselessness) & $1376(61.2)$ & $1606(15.4)$ & \\
\hline $\begin{array}{l}\text { Il (Stupor, lethargy, hypersomnia, somnolence, } \\
\text { drowsiness) }\end{array}$ & $354(15.7)$ & $257(2.5)$ & \\
\hline III (Deep coma, coma, semicoma) & $244(10.8)$ & $108(1.0)$ & \\
\hline Respiratory rate, median (IQR) & $24(24-30)$ & $20(18-20)$ & <. 0001 \\
\hline Systolic blood pressure, median (IQR) & $110(93-140)$ & $137(120-156)$ & $\begin{array}{l}< \\
0.0001\end{array}$ \\
\hline
\end{tabular}

\section{Comparison of mortality by items included in qSOFA score}

Figure 2 shows the mortality by items included in qSOFA. The proportion of patients discharged to death was significantly higher in those with altered mental status positive than negative (344/4332 [7.94\%] vs. $336 / 8314$ [4.04\%]; $p<0.0001)$, with respiratory rate $>21 / \min$ than $\leq 21 / \min (365 / 3945$ [9.25\%] vs. 
$315 / 8701$ [3.62\%]; $p<0.0001$ ), and with systolic blood pressure $\leq 100 \mathrm{mmHg}$ than $>100 \mathrm{mmHg}$ $(172 / 1510[11.39 \%]$ vs. $508 / 11,136[4.56 \%] ; p<0.0001)$.

\section{Comparison of mortality by qSOFA score}

Figure 3 shows the mortality by qSOFA score. Mortality increased with increasing qSOFA score (Score 0: 128/5430 [2.36\%], Score 1: 287/4966 [5.78\%], Score 2: 201/1929 [10.42\%], Score 3: 64/321 [19.94\%], $p<$ $0.0001)$.

\section{Comparison of mortality by qSOFA positive or negative}

Table 2 shows the mortality by qSOFA positive (score $\geq 2$ ) or negative $(\leq 1)$ as determined by a multivariable logistic regression model. The proportion of patients discharged to death was significantly higher for qSOFA positive than negative (265/2250 [11.78\%] vs. 415/10,396 [3.99\%]; AOR 2.909; 95\% Cl $2.469-3.428, p<0.0001)$. For qSOFA positive/negative, the specificity and sensitivity were $83.4 \%$ (9981 / $(9981+1985))$ and $40.0 \%,(265 /(265+415))$, respectively. The area under the ROC curve (AUC-ROC) of qSOFA positive/negative was 0.61 (Fig. 4).

Table 2

Outcomes at hospital discharge of logistic regression analysis by qSOFA positive (score $\geq 2$ ) or negative $(\leq 1)$

\begin{tabular}{|c|c|c|c|c|c|c|}
\hline & $\%(n / N)$ & $\%(n / N)$ & $\begin{array}{l}\text { Crude OR } \\
(95 \% \mathrm{Cl})\end{array}$ & $p_{\text {Value }}$ & $\begin{array}{l}\text { Adjusted OR* } \\
\text { (95\% Cl) }\end{array}$ & $p_{\text {Value }}$ \\
\hline \multirow[t]{2}{*}{$\begin{array}{l}\text { Discharge to } \\
\text { death }\end{array}$} & $\begin{array}{l}\text { qSOFA } \\
\text { score } \geq 2\end{array}$ & $\begin{array}{l}\text { qSOFA score } \\
\leq 1\end{array}$ & & & & \\
\hline & $\begin{array}{l}11.78 \\
(265 / 2250)\end{array}$ & $\begin{array}{l}3.99 \\
(415 / 10,396)\end{array}$ & $\begin{array}{l}3.211(2.737- \\
3.773)\end{array}$ & $\dot{0}_{0.0001}$ & $\begin{array}{l}2.909(2.469- \\
3.428)\end{array}$ & $<.0001$ \\
\hline \multicolumn{7}{|c|}{ *Adjusted for age, sex } \\
\hline \multicolumn{7}{|c|}{ ORs were calculated for qSOFA score $\geq 2$ vs $\leq 1$} \\
\hline \multicolumn{7}{|c|}{ qSOFA quick Sequential Organ Failure Assessme } \\
\hline
\end{tabular}

\section{Discussion}

From our analysis of the population-based ORION registry in Osaka, Japan, this study revealed that the proportion of patients discharged to death was significantly higher for qSOFA positive than negative in patients with sepsis or suspected sepsis evaluated by EMS personnel in the prehospital setting. To our knowledge, this is the largest report using a population-based registry to have assessed the association of prognosis in patients with sepsis or suspected sepsis with qSOFA evaluated in the prehospital setting. Our findings not only provide basic epidemiological information on sepsis patients but may help to improve the emergency medical system in prehospital settings and the prognosis of these patients by immediately recognizing their severity and selecting the appropriate hospital for treatment. 
From the assessment of mortality by items included in qSOFA, the proportion of patients discharged to death was significantly higher in those with altered mental status positive than negative, with respiratory rate $>21 / \mathrm{min}$ than $\leq 21 / \mathrm{min}$, and with systolic blood pressure $\leq 100 \mathrm{mmHg}$ than $>100 \mathrm{mmHg}$ (Fig. 2). Mortality also increased with increasing qSOFA score (Fig. 3). These results were similar to those of previous reports $[2,5]$ and were also clarified in this population based study.

The present multivariable logistic regression model showed that qSOFA positive was associated with discharge to death in patients with sepsis or suspected sepsis (Table 2). However, the specificity and sensitivity of qSOFA positive/negative were $83.4 \%$ and $40.0 \%$, respectively, and the AUC-ROC was 0.61 (Figure. 4). Several previous reports on the prehospital setting reported the sensitivity to prognosis outcome to be low. Tusgul et al reported that the sensitivity of 48-hour mortality for qSOFA positive in the prehospital setting was $68 \%(n=886)$ [3]. Askim et al reported that the specificity and the sensitivity of 7day mortality were $96 \%$ and $16 \%$, respectively $(n=1535)$ [4]. Miyamoto et al reported that the specificity and sensitivity of discharge to death were $68 \%$ and $56 \%$,respectively $(n=1849)$ [5]. The present study included 12,646 patients, which comprised the largest sample size reported to date, and the sensitivity was low, similar to that in these previous studies.

The reason for the ability to predict prognosis from qSOFA in the prehospital setting not being high might be due to the less frequent measurement of vital signs in the ambulance and the effect of treatment in the hospital not being taken into consideration. Most of the studies reporting the high prognostic ability of qSOFA have used 'worst value' in the emergency room in their calculation [11-13]. In contrast, most of the studies that used the 'initial value' in the emergency room for the calculation reported that the predictive power of qSOFA for prognosis was not high [4,11,14-17], and we considered this result to be supported by the results of the present study. Therefore, we think that it is important to measure vital signs repeatedly and to pay attention to the changes in vital signs when using qSOFA in the prehospital setting.

Nevertheless, the results of this study have great significance because qSOFA can be easily used in the prehospital setting, and it reflects the prognosis to some extent. The need to recognize septic patients in the prehospital setting is being emphasized more and more. The Surviving Sepsis Campaign task force published a new revision of the sepsis bundle (hour-1 bundle), which recommended the complete initiation of resuscitation and treatments of patients with sepsis within 1 hour from the time of triage in the emergency department $[18,19]$. Once EMS providers identified patients with sepsis or suspected sepsis, the prehospital qSOFA score was an effective tool in estimating mortality. It is important to use qSOFA properly after fully understanding its inspection characteristics. Further, as the population ages and the number of patients with sepsis increases throughout the world [20], if EMS personnel can identify suspected sepsis patients using qSOFA and start initial resuscitation in the prehospital setting, patient prognosis might improve.

Our study has some limitations. First, patients were included based on ICD-10 codes, not accurate diagnoses of patients with sepsis. We also chose the ICD-10 code for the disease suspected to have 
caused the sepsis. Second, the cause of death was unknown and might not be sepsis. Third, we did not compare the prehospital qSOFA score with other severity or prehospital screening tools because the information recorded in the ORION registry is limited. Fourth, patients with a do-not-resuscitate indication prior to admission were not excluded.

\section{Conclusions}

The qSOFA as evaluated by EMS personnel in the prehospital setting might be useful for predicting prognosis in patients with sepsis or suspected sepsis.

\section{Abbreviations}

AOR: adjusted odds ratio, AUC-ROC: area under the receiver operating curve, Cl: confidence interval, IQR: interquartile range, JCS: Japan Coma Scale, ORION: Osaka Emergency Information Research Intelligent Operation Network, qSOFA: quick Sequential Organ Failure Assessment.

\section{Declarations}

\section{Ethics approvals and consent to participate}

This study was approved by the Ethics Committee of the Osaka University Graduate School of Medicine (No. 15003). Personal identifiers were removed beforehand from the ORION database, and thus the patients' right to informed consent was waived.

\section{Consent for publication}

Not applicable.

\section{Availability of data and materials}

The data that support the findings of this study are available from the ORION database, but the availability of these data is restricted.

\section{Competing interests}

We certify that the authors declare no ethical or financial conflicts of interest in relation to this manuscript.

\section{Funding}

This study was supported by the Japan Society of the Promotion of Science KAKENHI (grant no. JP18H02902).

\section{Author's contributions}


TH analysed the data and wrote the first draft of this manuscript. TK reviewed all statistical analyses and critically revised this manuscript. YK, and $\mathrm{YU}$ interpreted the data and critically revised this manuscript. HO, YM, and TS supervised the interpretation of the data and critically revised this manuscript. All of the authors read and approved the final manuscript.

\section{Acknowledgements}

The authors thank the emergency medical service personnel, nurses, and emergency physicians who participated in the ORION. We thank our colleagues from Osaka University Center of Medical Data Science and Advanced Clinical Epidemiology Investigator's Research Project for providing their insight and expertise for our research.

\section{References}

1. Singer M, Deutschman CS, Seymour CW, Shankar-Hari M, Annane D, Bauer M, et al. The Third International Consensus Definitions for Sepsis and Septic Shock (Sepsis-3). JAMA. 2016;315:80110.

2. Seymour CW, Liu VX, Iwashyna TJ, Brunkhorst FM, Rea TD, Scherag A, et al. Assessment of Clinical Criteria for Sepsis: For the Third International Consensus Definitions for Sepsis and Septic Shock (Sepsis-3). JAMA. 2016;315:762-74.

3. Tusgul S, Carron PN, Yersin B, Calandra T, Dami F. Low sensitivity of qSOFA, SIRS criteria and sepsis definition to identify infected patients at risk of complication in the prehospital setting and at the emergency department triage. Scand J Trauma Resusc Emerg Med. 2017;25:108.

4. Askim A, Moser F, Gustad LT, Stene H, Gundersen M, Åsvold BO, et al. Poor performance of quickSOFA (qSOFA) score in predicting severe sepsis and mortality - a prospective study of patients admitted with infection to the emergency department. Scand J Trauma Resusc Emerg Med. 2017;25:56.

5. Miyamoto K, Shibata N, Nakashima T, Kato S. Prehospital quick sequential organ failure assessment as a tool to predict in-hospital mortality. Am J Emerg Med. 2018;36:1832-6.

6. Dorsett M, Kroll M, Smith CS, Asaro P, Liang SY, Moy HP. qSOFA has poor sensitivity for prehospital identification of severe sepsis and septic shock. Prehosp Emerg Care. 2017;21:489-97.

7. Koyama S, Yamaguchi Y, Gibo K, Nakayama I, Ueda S. Use of prehospital qSOFA in predicting inhospital mortality in patients with suspected infection: a retrospective cohort study. PloS One. 2019;14:e0216560.

8. Okamoto J, Katayama Y, Kitamura T, Sado J, Nakamura R, Kimura N, et al. Profile of the ORION (Osaka emergency information Research Intelligent Operation Network system) between 2015 and 2016 in Osaka, Japan: a population-based registry of emergency patients with both ambulance and in-hospital records. Acute Med Surg. 2019;6:12-24. 
9. von Elm E, Altman DG, Egger M, Pocock SJ, Gøtzsche PC, Vandenbroucke JP, STROBE Initiative. The Strengthening the Reporting of Observational Studies in Epidemiology (STROBE) statement: guidelines for reporting observational studies. J Clin Epidemiol. 2008;61:344-9.

10. Ohta T, Waga S, Handa W, Saito I, Takeuchi K. New grading of level of disordered consciousness (Author's Transl) [Article in Japanese]. No Shinkei Geka. 1974;2:623-7.

11. Jiang J, Yang J, Mei J, Jin Y, Lu Y. Head-to-head comparison of qSOFA and SIRS criteria in predicting the mortality of infected patients in the emergency department: a meta-analysis. Scand J Trauma Resusc Emerg Med. 2018;26:56.

12. Freund $\mathrm{Y}$, Lemachatti $\mathrm{N}$, Krastinova $\mathrm{E}$, Van Laer M, Claessens $\mathrm{YE}$, Avondo A, et al. Prognostic accuracy of Sepsis-3 criteria for in-hospital mortality among patients with suspected infection presenting to the emergency department. JAMA. 2017;317:301-8.

13. Henning DJ, Puskarich MA, Self WH, Howell MD, Donnino MW, Yealy DM, et al. An emergency department validation of the SEP-3 sepsis and septic shock definitions and comparison with 1992 consensus definitions. Ann Emerg Med. 2017;70:544-2.e5.

14. Goulden R, Hoyle MC, Monis J, Railton D, Riley V, Martin P, et al. qSOFA, SIRS and NEWS for predicting inhospital mortality and ICU admission in emergency admissions treated as sepsis. Emerg Med J. 2018;35:345-9.

15. Ranzani OT, Prina E, Menéndez R, Ceccato A, Cilloniz C, Méndez R, et al. New sepsis definition (Sepsis-3) and community-acquired pneumonia mortality. a validation and clinical decision-making study. Am J Respir Crit Care Med. 2017;196:1287-97.

16. González Del Castillo J, Julian-Jiménez A, González-Martínez F, Álvarez-Manzanares J, Piñera P, Navarro-Bustos C, et al. Prognostic accuracy of SIRS criteria, qSOFA score and GYM score for 30-daymortality in older non-severely dependent infected patients attended in the emergency department. Eur J Clin Microbiol Infect Dis. 2017;36:2361-9.

17. Moskowitz A, Patel PV, Grossestreuer AV, Chase M, Shapiro NI, Berg K, et al. Quick Sequential Organ Failure Assessment and Systemic Inflammatory Response Syndrome criteria as predictors of critical care intervention among patients with suspected infection. Crit Care Med. 2017;45:1813-9.

18. Levy MM, Evans LE, Rhodes A. The Surviving Sepsis Campaign Bundle: 2018 Update. Crit Care Med. 2018;46(6):997-1000.

19. Spiegel R, Farkas JD, Rola P, Kenny JE, Olusanya S, Marik PE, et al. The 2018 Surviving Sepsis Campaign's Treatment Bundle: when guidelines outpace the evidence supporting their use. Ann Emerg Med. 2019;73:356-8.

20. Rudd KE, Johnson SC, Agesa KM, Shackelford KA, Tsoi D, Kievlan DR, et al. Global, regional, and national sepsis incidence and mortality, 1990-2017: analysis for the Global Burden of Disease Study. Lancet. 2020;395:200-11.

\section{Figures}




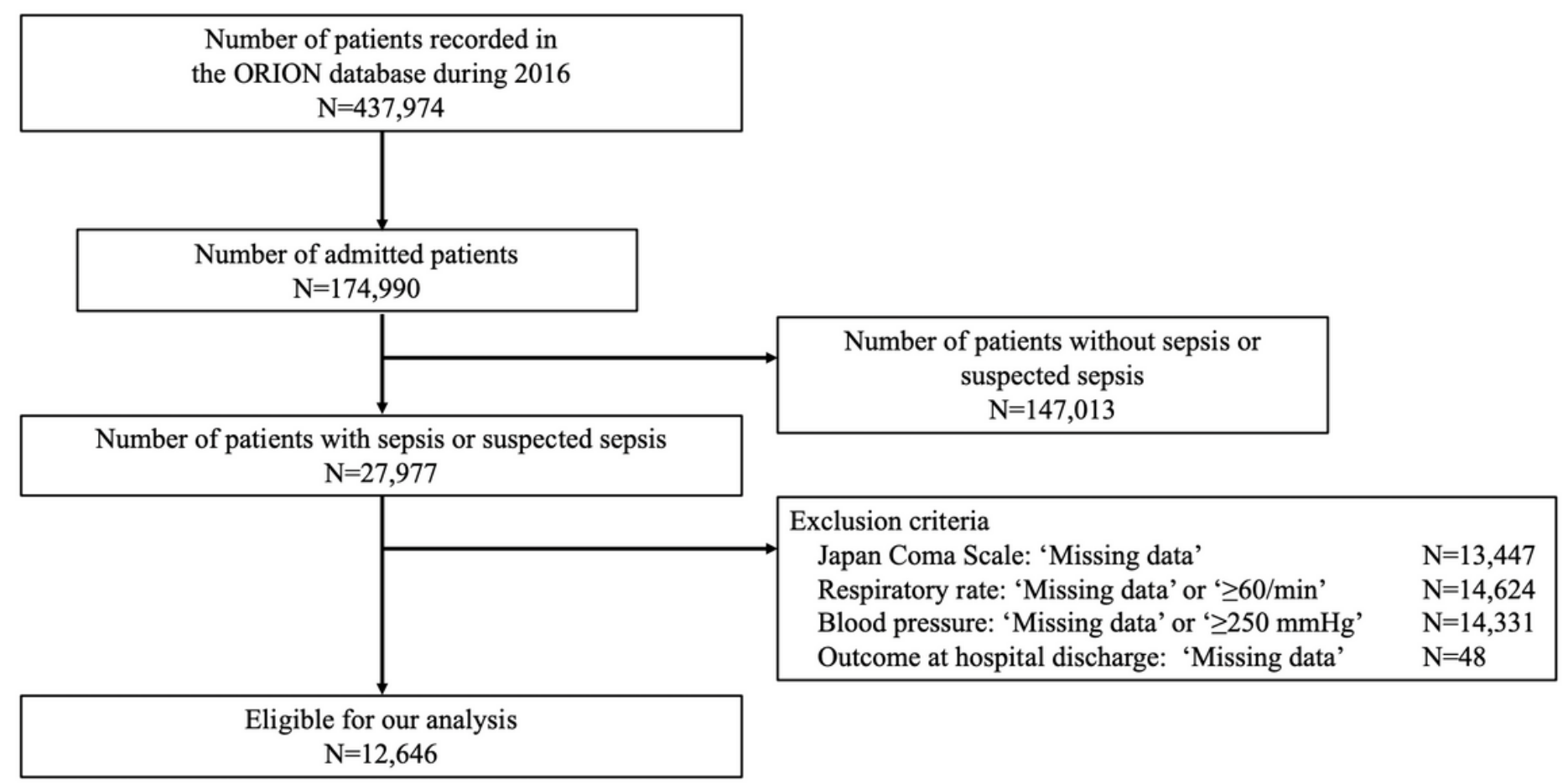

\section{Figure 1}

Patient flow in this study 
$p<0.001$, respectively

$\% 15$

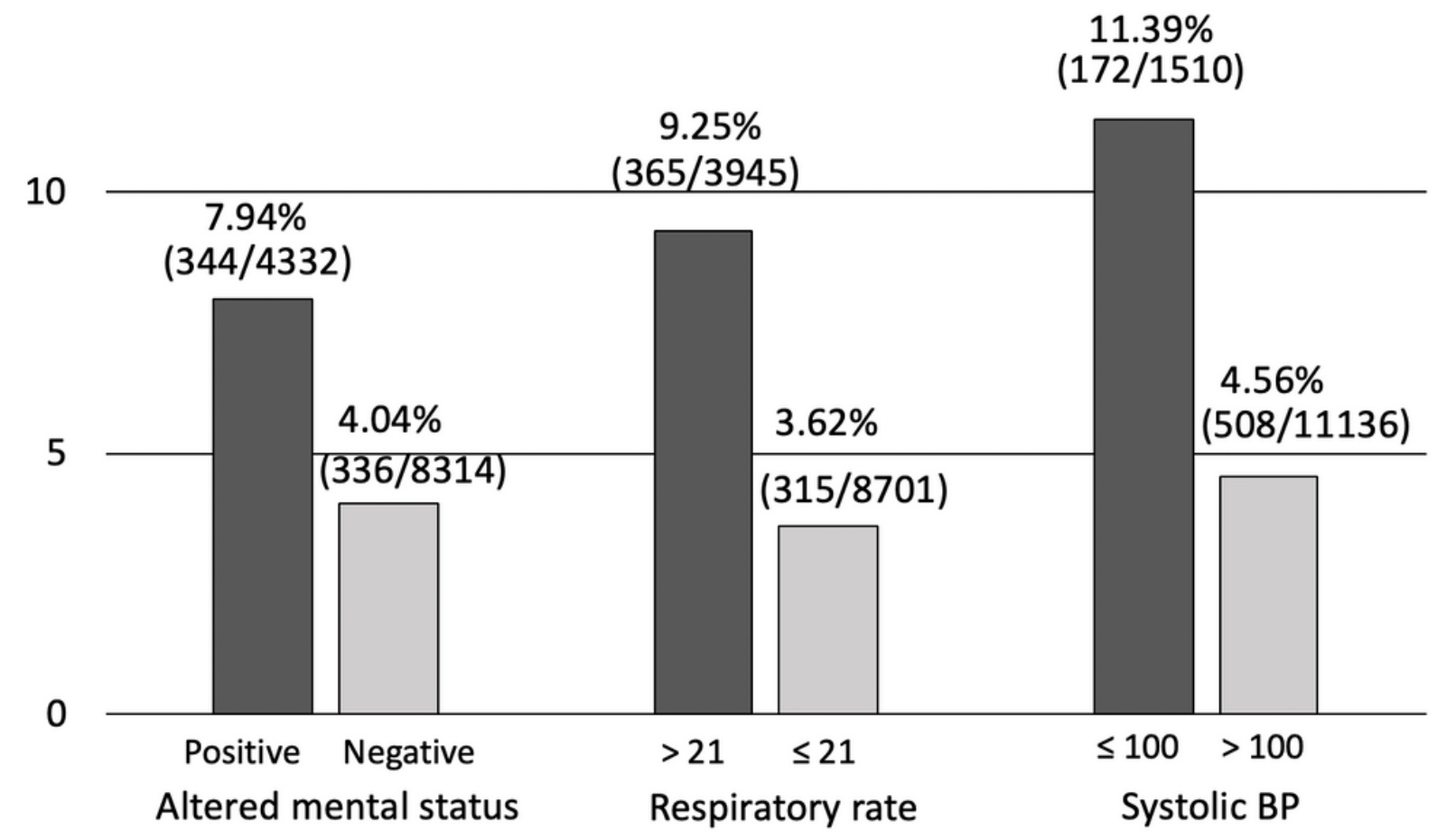

Figure 2

Comparison of mortality by items included in the qSOFA score. Discharge to death was significantly higher in patients with altered mental status positive than negative, with respiratory rate $>21 / \mathrm{min}$ than $\leq 21 / \mathrm{min}$, and with systolic blood pressure $\leq 100 \mathrm{mmHg}$ than $>100 \mathrm{mmHg}$. qSOFA quick Sequential Organ Failure Assessment 


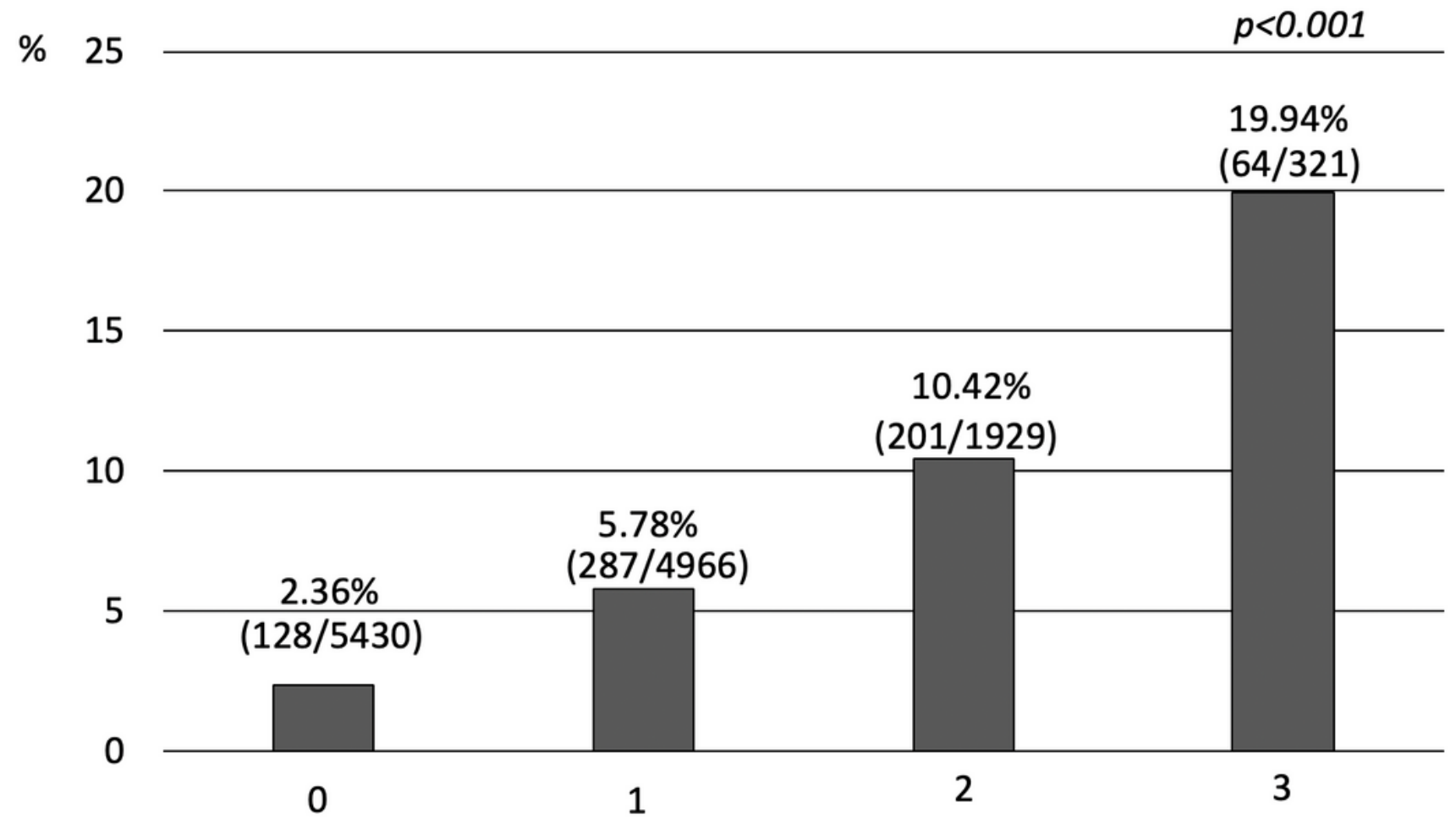

Figure 3

Comparison of mortality by qSOFA score. Mortality increased with increasing qSOFA score. qSOFA quick Sequential Organ Failure Assessment 


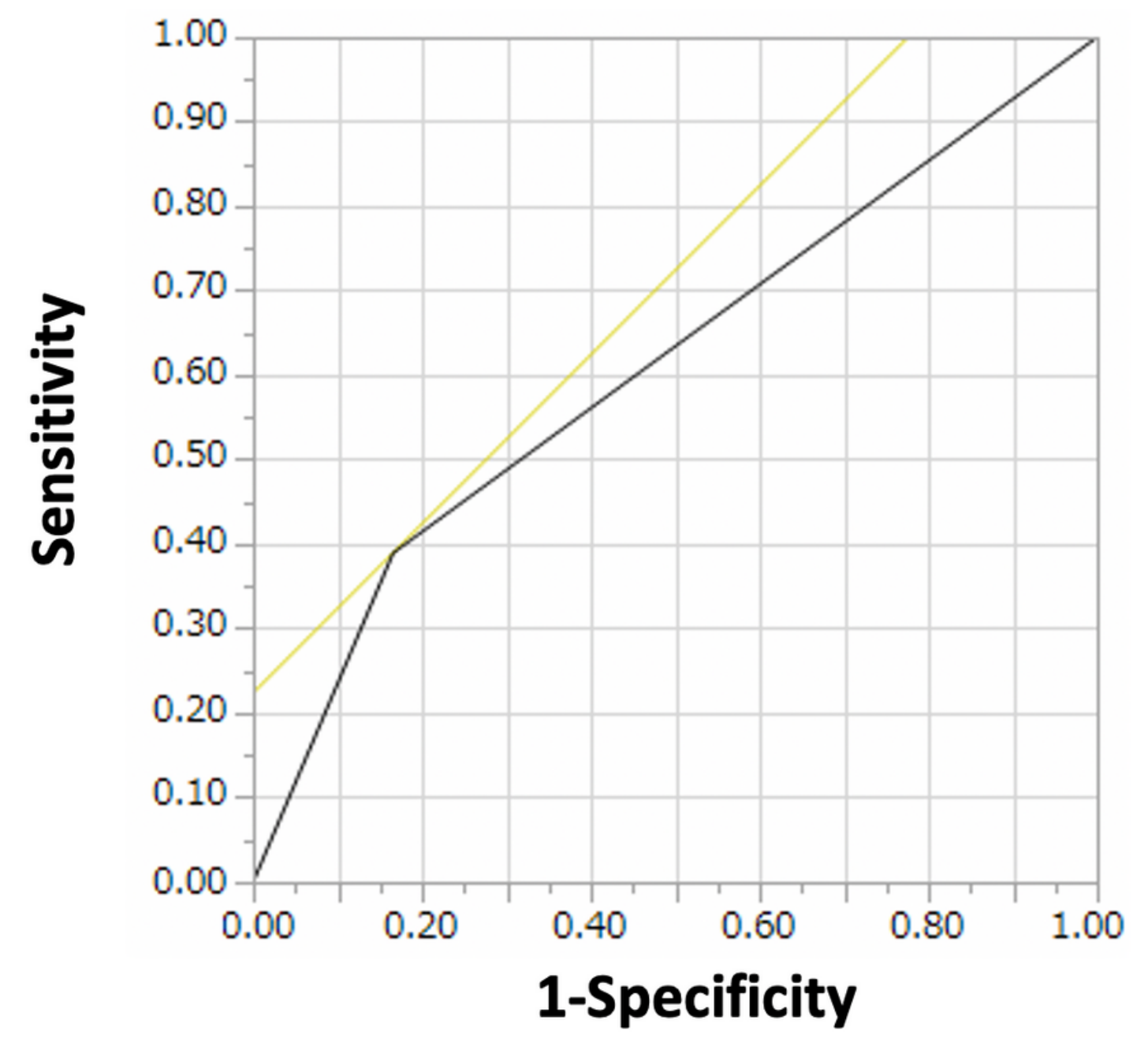

Figure 4

AUC-ROC of qSOFA positive/negative. With qSOFA positive/negative, the specificity and sensitivity were $83.4 \%$ and $40.0 \%$, respectively. The AUC-ROC of qSOFA positive/negative was 0.61 . AUC-ROC area under the receiver operating characteristic curve, qSOFA quick Sequential Organ Failure Assessment

\section{Supplementary Files}

This is a list of supplementary files associated with this preprint. Click to download.

- Supplementalmaterials.docx

- STROBEchecklistcrosssectional.docx 